\title{
Desarrollo del sistema nervioso humano. Perspectiva general del estadio prenatal
}

\section{hasta 2013}

\section{Development of the nervous system in humans. Overview of the prenatal stage until 2013}

\author{
Profa. Dra. Paloma Rohlfs Domínguez \\ Universidad de Extremadura (UNEX)
}

\section{Nota sobre la autora}

Profa $^{a}$ Dra. Paloma Rohlfs Domínguez. Dpto. de Psicología y Antropología, Universidad de Extremadura; Dpto. de Psicología Clínica, Experimental y Social, Universidad de Huelva; Dpto. de Psicología Social y Metodología del Comportamiento, y Facultad de Magisterio, ambas de la Euskalherriko Univertsitatea-Universidad del País Vasco.

Esta investigación fue realizada en el contexto contractual de la autora con la UNEX, sin financiación adicional.

Cualquier duda sobre este artículo podrá ser remitida a la segunda autora, a la siguiente dirección postal: Universidad de Extremadura. Facultad de Formación del Profesorado, Avda. de la Universidad s/n, 10003, Cáceres (España) o a la siguiente dirección de correo electrónico: palomaroh@unex.es 


\section{Resumen}

El estudio del origen y desarrollo del sistema nervioso humano es imprescindible para combatir los trastornos del desarrollo y las enfermedades neurodegenerativas. Por esta razón, la presente monografía tiene como objetivo revisar el estado actual de esta cuestión, centrándose específicamente en la fase prenatal de tal desarrollo. De acuerdo con este objetivo, se llevó a cabo una búsqueda electrónica entre 2003 y 2013 de literatura científica publicada en las bases de datos Academic Search Complete, Medline y Science Direct, incluyendo las siguientes palabras clave: desarrollo ontogenético, sistema nervioso humano y fase prenatal. A la luz de esta revisión, se concluye que en el origen y desarrollo prenatal del sistema nervioso humano están implicados toda una serie de eventos ontogenéticos perfectamente orquestados, que tienen lugar desde la fecundación del óvulo hasta el nacimiento del individuo. Estos eventos se pueden presentar de manera sucesiva, o bien de manera superpuesta. Se trata específicamente de los siguientes eventos: transformación del zigoto; neurulación primaria; neurogénesis; migración neuronal; agrupamiento neuronal; sinaptogénesis, mielinización y poda axónica. Además, se concluye que existen al menos dos cuestiones que ya no suscitan debate científico. El primero es sobre el hecho de que el origen y desarrollo prenatal del sistema nervioso humano muestra un patrón estereotipado. El segundo se refiere a que la acción combinada de la influencia externa (medio ambiente) e interna (genética) determina dicho patrón de desarrollo. Finalmente, se recomienda invertir un mayor esfuerzo investigador en el futuro en dilucidar varias cuestiones relativas a la migración neuronal y a la reorganización sináptica posterior a la poda axónica.

Palabras clave: sistema nervioso, desarrollo prenatal, migración neuronal, sinaptogénesis, mielinización, poda axónica. 


\begin{abstract}
The study the origin and development of the nervous system in humans has gained increasing attention since its understanding is useful in the treatment of developmental disorders and neurodegenerative diseases. We aimed to review its current status, focusing on the prenatal stage. We searched papers from 2003 to 2013 in academic data-bases such as Academic Search Complete, Medline, and Science Direct, including the following keywords: ontogenetic development, human nervous system and prenatal stage. We conclude that a series of perfectly orchestrated ontogenetic events, which take place from fecundation of the ovum to the birth of the individual, are involved in the origin and prenatal development of the human nervous system. These events may occur either successively or in an overlapping manner. These events are the following: transformation of the zygote; primary neurulation; neurogenesis; neuronal migration; neuronal clustering; synaptogenesis; myelination and synaptic pruning. Moreover, we conclude that there are at least two issues that no longer spark scientific debate. The first one refers to the fact that the origin and prenatal development of the human nervous system shows a stereotyped pattern. The second one is about that the combined action of external (environment) and internal (genetics) influences determine the pattern of development. We recommend to focus on neuronal migration and synaptic reorganization after axonal pruning.
\end{abstract}

Keywords: nervous system, prenatal development, neural migration, synaptogenesis, myelination, axonic pruning. 


\section{Introducción}

El desarrollo ontogenético del sistema nervioso humano describe el desarrollo de éste desde el momento de la fertilización del óvulo, pasando por su desarrollo embrionario-fetal y postnatal, hasta la vida adulta. Se trata de un proceso especialmente delicado y complejo, pues su misión última consiste en lograr el establecimiento y mantenimiento eficaz de toda una serie de circuitos neuronales de alta precisión. Si estos circuitos se desarrollan con normalidad ( $\sin$ alteraciones), el individuo podrá experimentar y disfrutar plenamente de cualquier tipo de vivencia (pensamiento, sentimiento, percepción, o emoción), así como ejecutar con pericia cualquier acción o conducta (hablar, andar, o respirar, entre otras). Por esta razón, nos encontramos ante un proceso de vital importancia.

Identificar y producir nuevos conocimientos en este campo es una estrategia clave para el tratamiento de los trastornos del desarrollo, como por ejemplo, el autismo, así como de enfermedades neurodegenerativas, como por ejemplo, la de Alzheimer o la de Parkinson.

La pregunta de investigación a la que pretender responder este trabajo de revisión es cuáles son las últimas evidencias sobre la secuencia de eventos biológicos implicados en el origen y desarrollo prenatal del sistema nervioso humano y sobre esos eventos.

Esta monografía se centra específicamente en discutir el conocimiento actual sobre los principales eventos biológicos del origen y del desarrollo ontogenético del sistema nervioso humano y su secuencia, centrándose exclusivamente en su fase prenatal, a lo que se dedica la práctica totalidad del texto. Este trabajo supone una actualización del conocimiento aportado mediante trabajos de investigación publicados entre 2003 y 2013. Por lo tanto, no se trata de un trabajo longitudinal sobre el desarrollo prenatal del 
sistema nervioso humano, sino una descripción del tema, realizada de literatura especializada. El manuscrito culmina con la presentación de una serie de conclusiones sobre la temática que nos ocupa, así como de recomendaciones sobre futuras aportaciones.

Hasta la fecha no se ha publicado un artículo de estas características sobre esta temática en castellano. De hecho, aunque en el pasado ya se descubriera la ocurrencia de cada uno de los eventos ontogenéticos aquí tratados, y por lo tanto, se identificara su secuencia, no se ha dedicado un espacio editorial a publicar una revisión de literatura actualizada hasta 2013 sobre ello, por lo que esta aportación brinda la oportunidad de cubrir esta brecha.

\section{Revisión de la literatura}

\section{Origen del sistema nervioso}

El comienzo de la formación del sistema nervioso humano es una única célula original, el óvulo fertilizado o zigoto, de la que surgirán todas las células diferenciales que configuran el organismo de un individuo, incluidas las neuronas. Mediante sucesivas divisiones celulares mitóticas - dos, cuatro, ocho, dieciséis y treinta y dos células-, el zigoto se transforma, durante el trayecto que recorre para descender de la trompa de Falopio con destino al útero, progresivamente en mórula (Sadler, 2009). Este proceso tiene lugar durante los tres primeros días posteriores a la fecundación (Chuva de Sousa Lopes y Mummery, 2009). Las células de la mórula son células madre (Strelchenko y Verlinsky, 2006); células totipotenciales, es decir, capaces de generar cualquier célula del organismo (Mancheño Maciá y Giménez Ribotta, 2005). A continuación, y ya implantado el zigoto en el útero, también mediante división mitótica o blastulación, la mórula se convierte en blástula, forma embriológica temprana de estructura esférica de una sola capa celular rellena de fluido. A este proceso se le denomina blastulación. No obstante, 
el blastocito temprano, estructura precursora de la blástula final, se forma con anterioridad a la implantación del zigoto en el útero (Sadler, 2009) (véase figura 1).
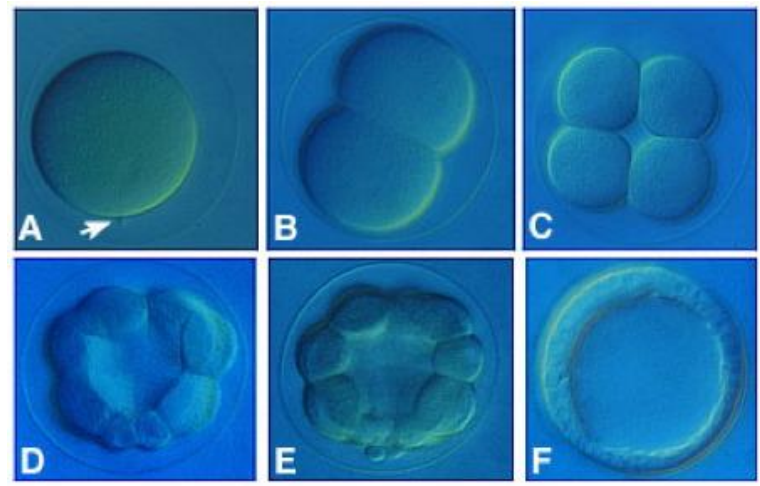

Figura 1

Divisiones mitóticas de un zigoto de la Lumbriculus Variegatus

A. Fertilización del óvulo). B-D. Zigoto de 2, 4 y 8 células, respectivamente. E. Zigoto de entre 16 y 32 células (mórula) (tomadas de Hardin 2005a, con permiso). F. Zigoto en fase de blástula (cortesía del Dr. Chuck Ettensohn, de la Universidad Carnegie-Mellon).

A partir de este momento, las células del zigoto pierden progresivamente su rasgo de totipotencialidad, y pasan a ser multipotenciales, es decir, capaces de diferenciarse sólo en algunos tipos distintos de células (Mancheño Maciá y Giménez Ribotta, 2005). Finalmente, determinados movimientos celulares de la blástula, proceso denominado como gastrulación, transformarán al zigoto en una gástrula (véase figura 2). 


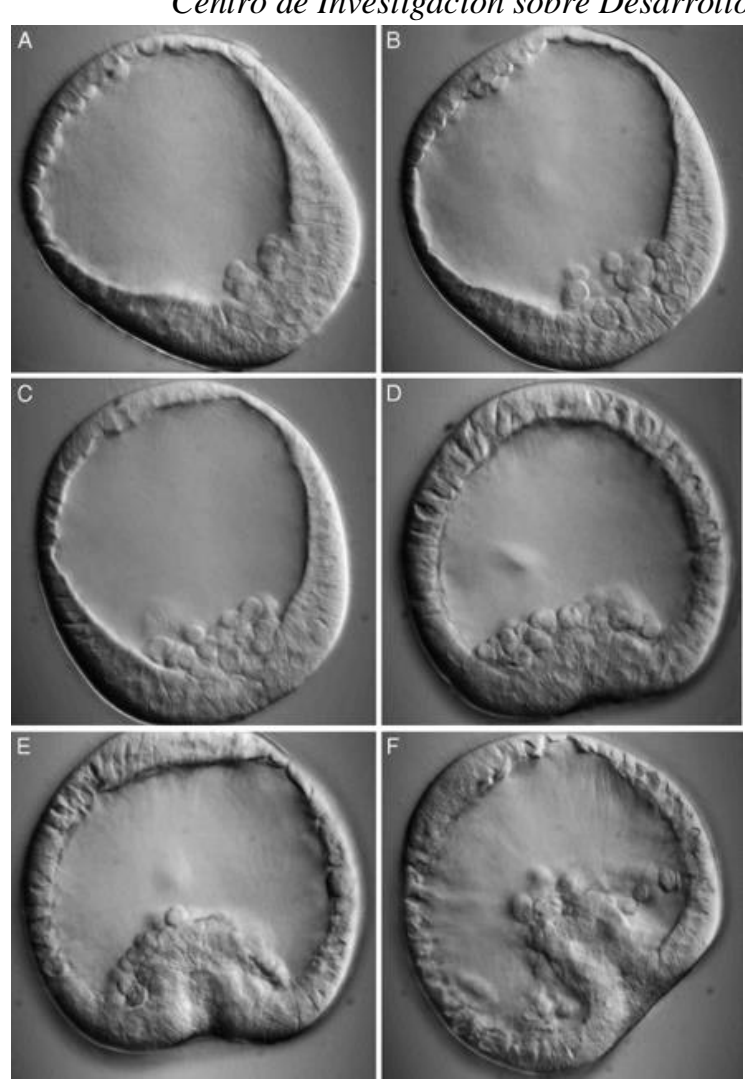

Figura 2

Ampliación microscópica de las fases de la gastrulación embrionaria de la Lumbriculus Variegatus

A-E. Movimientos celulares progresivos, formando la gástrula. F. Gástrula semitardía (cortesía del Dr. David McClay, de la Universidad de Duke).

La gástrula presenta tres capas de células claramente diferenciadas: ectodermo, mesodermo y endodermo, respectivamente (Pinel, 2007) (véase figura 3). 


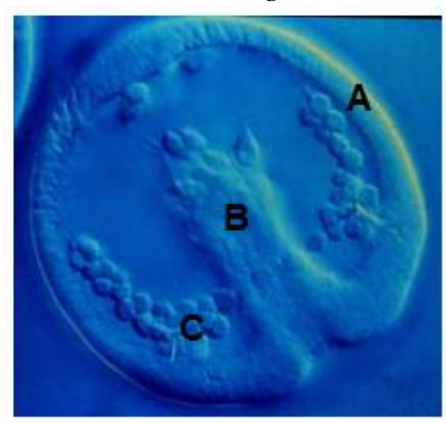

Figura 3

Ampliación microscópica de la gástrula tardía del erizo de mar

A. Ectodermo. B. Mesodermo y C. Endodermo (adaptada de Hardin, 2005b, y por cortesía del Dr. Charles Ettensohn). El erizo de mar es una de las especies en las que se estudió el desarrollo embrionario por primera vez (Hardin, 2005b).

Los huesos y la masa muscular se originan desde el mesodermo (Sadler, 2009; Long, 2012), y los diferentes órganos, tales como el páncreas, el esófago o el estómago, derivan del endodermo (Cheng, Tiyaboonchai y Gaude, 2013). El sistema nervioso y sus diferentes estructuras se originan a partir del ectodermo (Kiernan y Rajakumar, 2013). En este momento, el zigoto recibe el nombre de gástrula tardía (Beane, Gross y McClay, 2006), y hablamos de progenitores, en lugar de células multipotenciales, para referirnos a las células que lo componen. Los progenitores dan lugar a exclusivamente a células de un linaje celular específico de la zona corporal (por ejemplo, de un órgano o músculo) y, por lo tanto, de la función que esta zona corporal realiza comúnmente (Mancheño Maciá y Giménez Ribotta, 2005).

\section{Desarrollo embrionario del sistema nervioso}

Primeros eventos embrionarios. El sistema nervioso comienza a formarse cuando el embrión tiene aproximadamente dos semanas. En el decimoséptimo día de desarrollo, aproximadamente, el ectodermo comienza a sufrir cambios estructurales de gran relevancia. En concreto, se produce la emergencia de la placa neural o 
neuroectodermo a partir del ectodermo, por inducción neural de la notocorda y del mesodermo (véase figura 4).
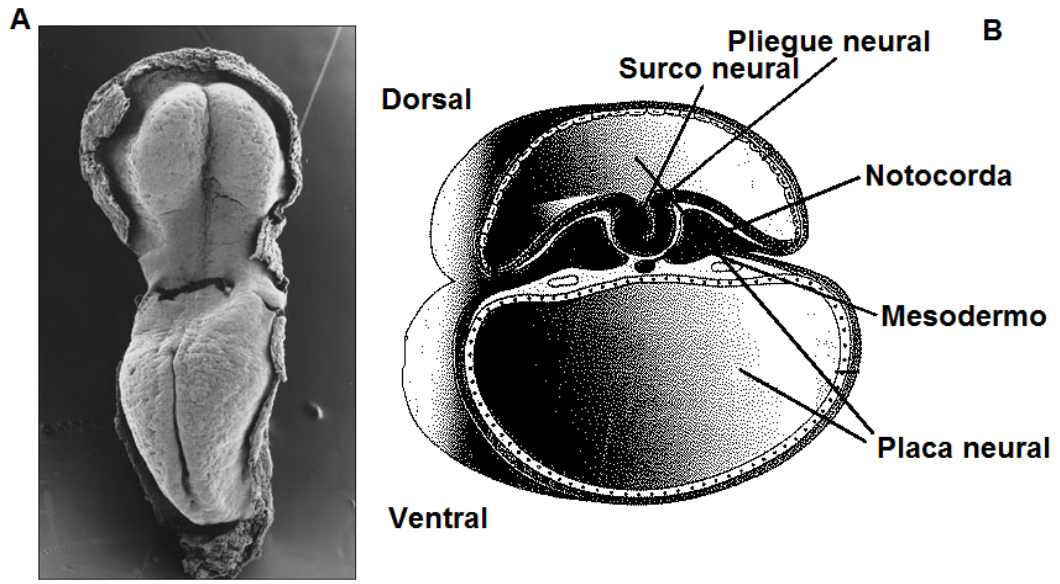

Figura 4

\section{Ampliación microscópica de la placa neural y sección transversal de notocorda y mesodermo}

A. Ampliación microscópica de la placa neural emergida a partir del decimoséptimo día de desarrollo (cortesía de la Dra. Kathy Sulik, de la Universidad de Carolina del Norte). B. Notocorda y mesodermo de la sección transversal de un embrión entre la segunda y la tercera semana de desarrollo embrionario, aproximadamente (adaptada de Sadler, 2009).

La inducción es el mecanismo por el que un tejido o estructura, en este caso, el ectodermo, se ve forzado a sufrir cambios como consecuencia de la acción de otro/s tejido/s o estructura/s, en este caso, la notocorda y el mesodermo.

En el decimoctavo día de desarrollo aproximadamente, los extremos laterales de la placa neural se elevan formando los pliegues neurales, mientras que su porción media dará lugar al surco neural. Durante los diez días siguientes, los pliegues de éste se fusionan progresivamente formando los primeros vestigios del tubo neural. El tubo neural se compone de células madre que darán lugar tanto a futuras células nerviosas -neuronascomo a células gliales (Corr, 2008) (células multifuncionales de apoyo a la función y estructura neuronal). El sistema nervioso central deriva del tubo neural (Kiernan y 
Rajakumar, 2013). Dicha fusión comienza en la zona cervical y continúa hacia las regiones cefálica y caudal (Sadler, 2009). A su vez, esta fusión dará lugar a la convergencia gradual de la cresta de cada uno de ellos, que culminará en la formación de la denominada cresta neural en la zona dorsal del tubo neural. Ésta es una estructura clave en el desarrollo del sistema nervioso de los vertebrados (véase figura 5).

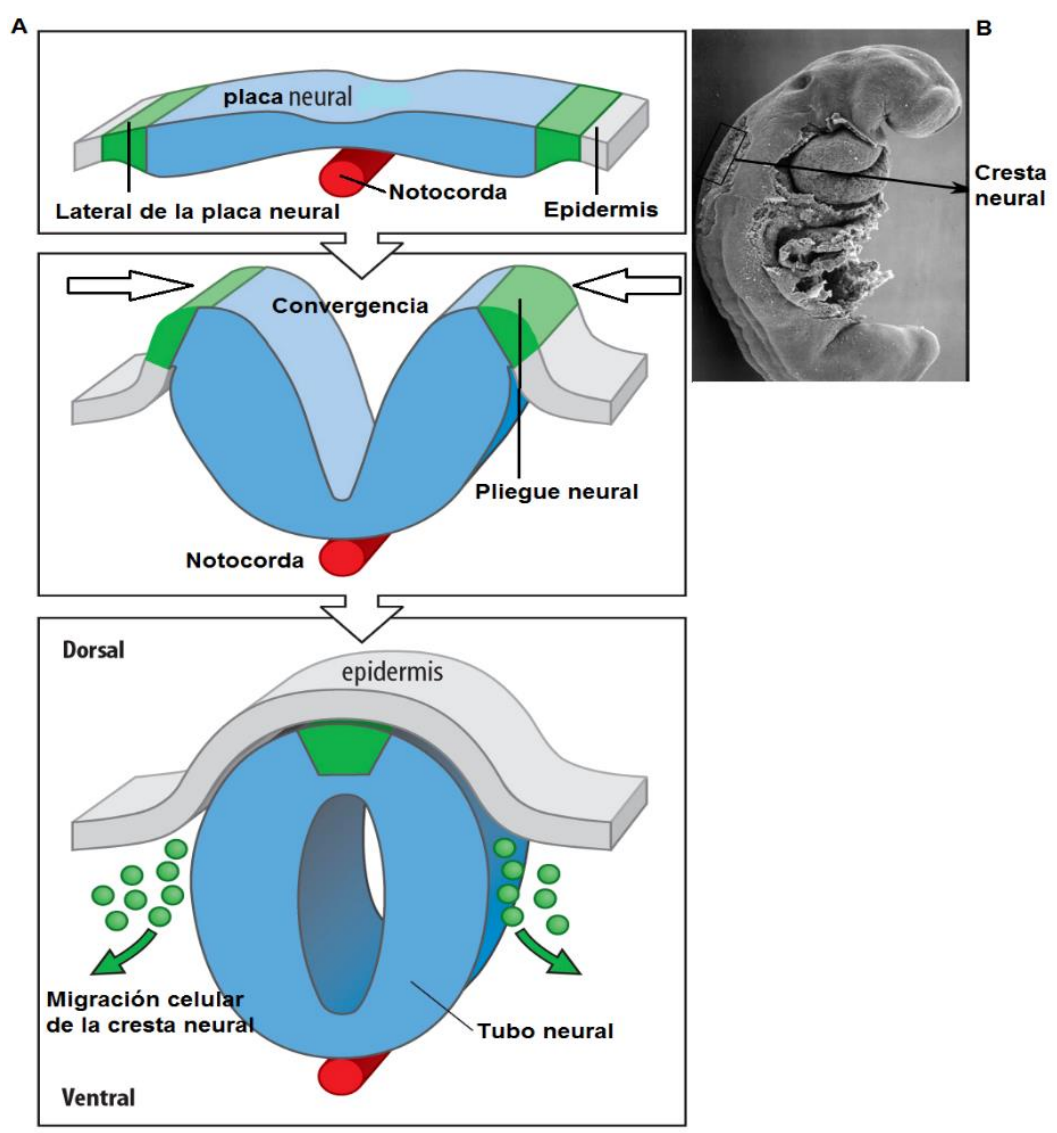

Figura 5

Formación de la cresta neural y ampliación microscópica de un zigoto

A. Formación de la cresta neural (adaptada de Staveley, 2013). B. Ampliación microscópica de un zigoto en el decimoquinto día de desarrollo (adaptada de Hill 2013a, por cortesía de la Dra. Sulik).

Una vez formada la cresta neural, un grupo de células de una vasta variedad de tipos, tales como el óseo, el neuronal o el cartilaginoso, migrarán activamente, al menos en el ser humano y en el ratón, desde esta zona hacia el mesodermo adyacente (Huang y 
Saint-Jeannet, 2004; Sadler, 2009; Betters, Liu, Kjaeldgaard, Sundström y García-Castro, 2010). Un reciente trabajo de revisión -Milet y Monsoro-Burg, 2012- sitúa, sin embargo, la migración celular de la cresta neural de algunos vertebrados, por ejemplo de la rana, en la fase de gastrulación. En cualquier caso, esta migración celular está implicada, entre otras transformaciones del embrión, en el desarrollo de su futuro sistema nervioso periférico (Dickinson, Machnicki, Ali, Zhang y Sohal, 2004; Kalat, 2004; Kiernan y Rajakumar, 2013).

La formación del tubo neural alcanza su clímax cuando tanto el neuroporo craneal como el caudal, situados en los respectivos extremos superior o anterior e inferior o posterior del embrión, se cierran aproximadamente en el vigésimo quinto y vigésimo séptimo día desarrollo, respectivamente (Sadler, 2009) (véase figura 6).

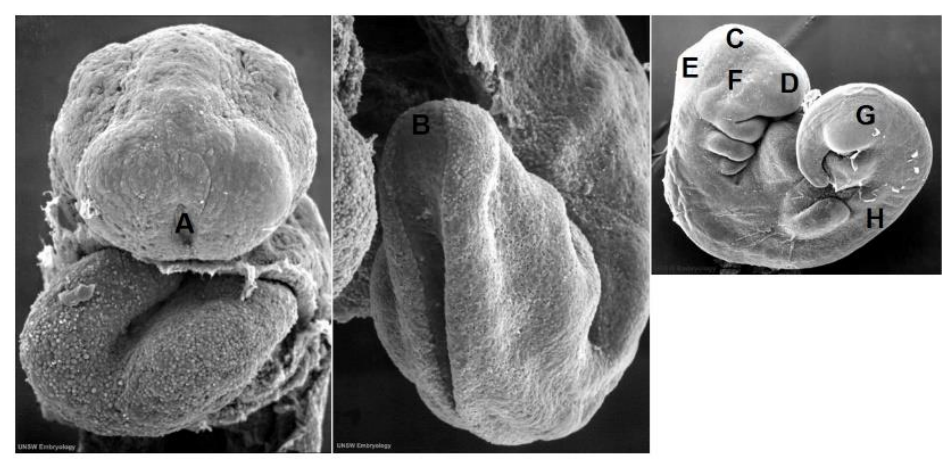

Figura 6

Ampliación microscópica de ambos neuroporos

A-B. Neuroporos anterior y posterior, respectivamente, cerrados (cortesía de la Dra. Sulik). C-H. Ampliación microscópica de un embrión (cuarta semana de su desarrollo), donde $\mathrm{C}=$ mesencéfalo; $\mathrm{D}=$ prosencéfalo; $\mathrm{E}=$ rombencéfalo; $\mathrm{F}-\mathrm{G}=$ las regiones cefálica y caudal, respecivamente y $\mathrm{H}=$ el cordón espinal (adaptada de Hill 2013b, por cortesía de la Dra. Sulik). 
El cierre del tubo neural, junto con la formación de la cresta neural, es uno de los requisitos fisiológicos necesarios para que la migración celular descrita anteriormente pueda acontecer (Sadler, 2009).

Al conjunto de procesos fisiológicos de fusión de los pliegues neurales; formación de la cresta y del tubo neural y migración celular de la cresta neural se le denomina neurulación primaria.

A partir del cierre de sendos neuroporos, quedarán determinadas las dos grandes divisiones del sistema nervioso central. Por un lado, el extremo anterior o región cefálica del tubo neural, que pasará a diferenciarse en otras tres regiones -prosencéfalo, mesencéfalo y rombencéfalo- (Lim y Golden, 2007). Por otro lado, la región caudal del tubo neural dará lugar al cordón espinal (Fig. 6). Hacia la quinta semana de desarrollo embrionario, aproximadamente, el prosencéfalo desarrolla las vesículas telencefálicas, de cuyas paredes derivarán los hemisferios cerebrales, y cuyas cavidades acogerán a los futuros ventrículos. Asimismo, la cavidad del prosencéfalo dará lugar al diencéfalo con tres estructuras claramente diferenciadas: el epitálamo, el tálamo y el hipotálamo.

Desarrollo prenatal de las neuronas. El origen y progresivo desarrollo de las neuronas es un proceso imprescindible, pues está directamente implicado en la formación de las diferentes estructuras del sistema nervioso. El desarrollo embrionario de las neuronas atraviesa cinco fases superpuestas bien diferenciadas entre sí. En cada una de ellas ocurren diversos hitos biológicos que determinan la continuidad del desarrollo normal (libre de alteraciones) del sistema nervioso. A continuación, se exponen tales hitos biológicos.

Proliferación neuronal o neurogénesis. Se trata del proceso implicado en la generación de nuevas neuronas (Kriegstein y Noctor, 2004; Arias-Carrión, OlivaresBañuelos y Drucker-Colín, 2007). En el ser humano, este proceso comienza en el tercer 
mes de gestación, aproximadamente, y continúa hasta los dos y medio de edad (Semple,

Blomgren, Gimlin, Ferriero y Noble-Haeusslein, 2013).

Casi todas las neuronas y células gliales del sistema nervioso proliferan del neuroepitelio de las zonas ventricular (ZV) y subventricular (ZSV) del tubo neural (Cavada, 1988; Snell, 2007) del telencéfalo dorsal y ventral, respectivamente (Kriegstein y Noctor, 2004). La ZSV incluye tres zonas progenitoras de precursores neuronales localizadas en la denominada eminencia ganglionar del telencéfalo ventral, a saber: la eminencia ganglionar medial (EGM); la eminencia ganglionar lateral (EGL) y la eminencia ganglionar caudal (EGC) (Parnavelas, 2000; Hatten, 2002). Mientras que la $\mathrm{ZV}$ origina fundamentalmente neuronas, la ZSV produce tanto neuronas como células gliales (De Graaf-Peters y Hadders-Algra, 2006). Las neuronas producidas en la ZV son de tipo piramidal, es decir, neuronas excitatorias de proyección de la corteza. La ZSV, en contraste, origina interneuronas corticales, o sea neuronas inhibitorias no piramidales (Parnavelas, 2000; Kriegstein y Noctor, 2004). La ZV es la más tendiente a la proliferación neuronal, ya que allí emergen hasta un noventa por ciento de las neuronas de la corteza cerebral (Ayala, Shu y Tsai, 2007), la parte más extensa del sistema nervioso central de los mamíferos (Parnavelas, 2000; Pinel, 2007; Lossi, Alasia, Salio y Merigui, 2009; Dicou, 2009). La producción de neuroblastos y glioblastos en la cresta neural daré lugar, en cambio, a neuronas y a células gliales del sistema nervioso periférico (Hao, Bornstein, Vanden Berghe, Lomax, Young y Foong, 2013). Si bien, la cresta neural puede producir células de otros linajes, tales como el óseo, cartilaginoso o el tendinoso, entre otros (Le Douarin y Dupin, 2003; Milet y Monsoro-Burg, 2012).

Algunas células mádre neuroepiteliales del tubo neural, que son originalmente totipotenciales, se convierten efectivamente en progenitores neuronales que se transformarán en precursores neuronales o neuroblastos (Beltz y Sandeman, 2003; Lossi, 
Cantile, Tamagno y Merighi, 2005; Corr, 2008). Esto ocurrirá a medida que la diferenciación celular progrese. Otras células neuroepiteliales, en cambio, darán lugar a progenitores de células gliales que se convertirán en glioblastos (Lossi et al., 2005) y posteriormente en neuroglía, astroglía o macroglía del sistema nervioso. Los neuroblastos se generan en primer lugar -entre el segundo y el cuarto mes de gestación-, mientras que los glioblastos se forman, una vez terminada la formación de neuroblastos -entre el quinto mes de gestación y el primer año de vida- (Rivkin, 2000). Estos darán lugar a neuronas cuando desarrollen posteriormente sus prolongaciones características -las dendritas y los axones-. Las células madre gliales radiales residentes en la ZV y en la ZSV, por su parte, son también una fuente importante de precursores neuronales e incluso neuronas propiamente dichas (Kriegstein y Álvarez-Buylla, 2009).

Entre la vigésima y vigésimo cuarta semana de gestación, el embrión está dotado del cómputo prácticamente total de neuronas. Esta producción de neuronas varía según el momento cronológico del desarrollo embrionario-fetal y según la zona del sistema nervioso. Por ejemplo, las células nerviosas de las diferentes láminas de la corteza se producen en momentos embrionarios diferentes (Pinel, 2007). Aunque la mayoría de las neuronas se generan durante la gestación embrionaria-fetal, otras pueden generarse más tarde, incluso durante la edad adulta, como las neuronas del bulbo olfatorio (Luskin, 1993; Bédard y Parent, 2004; Arias-Carrión et al., 2007; Cayre, Canoll y Godman, 2009; Belvindrah, Nissant y Lledo, 2011) y del giro dentado hipocampal (Snyder, Kee y Wojtowicz, 2001; Beltz y Sandeman, 2003; Snyder, Hong, McDonald y Wojtowicz, 2005; Arias-Carrión et al., 2007; Lossi et al., 2009). Por lo tanto, la generación del número total de las neuronas no sigue un curso de desarrollo espaciotemporal simultáneo a lo largo del sistema nervioso. 
Migración y definición neuronal. Es el proceso por el que las células nerviosas viajan desde las zonas progenitoras mencionadas hasta su destino definitivo, bien el sistema nervioso central o el sistema nervioso periférico. Es un proceso crítico para la construcción estructural y funcional del sistema nervioso. En ambos casos, y sobre todo, en el caso de la migración neuronal hacia el sistema nervioso periférico, las neuronas han de recorrer largas distancias para llegar a su meta final Pinel, 2007; Corr, 2008). A pesar de este aparente hándicap, lo cierto es que la migración neuronal se produce rápidamente, siempre que se den las condiciones moleculares adecuadas en el medio interno y externo de las neuronas (Gupton y Waterman-Storer, 2006).

Al comienzo de la migración, aproximadamente entre el tercer y el quinto mes de gestación, las neuronas son inmaduras (Hatten, 2002), pues carecen de axón y dendritas (Kalat, 2004; Pinel, 2007), sus prolongaciones definitorias. La auténtica diferenciación de las neuronas entre sí ocurre gracias a la definición física de aquéllas que, a su vez, viene determinada por el destino final que las neuronas han de alcanzar dentro del sistema nervioso (Kiernan y Rajakumar, 2013). En el caso de algunas neuronas, tales prolongaciones emergen en forma de brotes axónicos y dendríticos, a medida que las neuronas alcanzan su posición final dentro del sistema nervioso. Cuando es así, los axones brotan durante la migración celular, mientras que las dendritas se desarrollan cuando la célula nerviosa se aproxima a su destino definitivo. En el caso de otras neuronas, en cambio, tanto los axones como las dendritas brotan, una vez que las células nerviosas ya lo han alcanzado (Kalat, 2004).

Existen dos tipos de migración neuronal, establecidos según la dirección en la que viajan las neuronas. Por un lado, la migración tangencial, en la que las neuronas migran en dirección paralela a las paredes del tubo neural. Ayala et al., (2007) han identificado dos rutas migratorias tangenciales principales: de la EGM a la neocorteza y al hipocampo 
y de la EGL al bulbo olfatorio. En la migración radial, en contraste, las neuronas viajan en dirección perpendicular a las paredes del tubo neural (Marin y Rubenstein, 2003; Ayala et al., 2007; Pinel, 2007). Este tipo de migración es utilizada por neuronas que, habiéndose originado en la ZV, contribuyen a la formación de la corteza cerebral, la médula espinal, el cuerpo estriado y el tálamo, entre otras estructuras cerebrales (Ayala et al., 2007).

Por otra parte, diferentes tipos de neuronas utilizan diferentes métodos de locomoción. Los más conocidos son el método de movimiento mediado por cambios en la localización del soma y el mediado por neuroglia. El primero de ellos se observa tanto en la migración radial como en la migración tangencial (Ayala et al., 2007; Pinel, 2007). En este caso, la neurona se desplaza cambiando la localización de su soma extendiendo y retrayendo su extensión en dirección hacia su destino final (Hatten, 2002; Ayala et al., 2007; Pinel 2007). El segundo de ellos, en cambio, sólo se observa en la migración radial. En este caso, las neuronas se desplazan utilizando una red formada por neuroglia radial (Ayala et al., 2007; Pinel, 2007).

La migración neuronal es un proceso que también sigue un curso espaciotemporal heterogéneo, ya que se sabe que distintos tipos de células, por ejemplo, las neuronas de las diferentes láminas de la corteza cerebral, migran a destinos diversos en momentos de desarrollo diferentes (Pinel, 2007). Tampoco es un proceso uniforme para todas las neuronas, pues algunas migran radialmente, mientras que otras migran tangencialmente. Además, se ha constatado que algunas pueden migrar primero tangencial y luego radialmente y viceversa (Parnavelas, 2000; Pinel, 2007; Métin, Vallee, Rakic y Bhide, 2008). Sin embargo, queda por averiguar, en su caso, qué tipo exactamente de neuronas sufren estos cambios de dirección, si sólo las que en un principio migran radialmente, o sólo las que lo hacen tangencialmente o ambas. También se desconoce qué tipo de neuronas sufren estos cambios de dirección, si las del sistema nervioso central o las del 
sistema nervioso periférico o ambas. Por otro lado, Kriegstein y Noctor (2004) han identificado que algunas neuronas de patrón migratorio radial cambian su forma celular y la velocidad de migración, además de la dirección durante su migración radial. Aún queda por dilucidar si esto también es aplicable a las neuronas de patrón migratorio tangencial. Finalmente, quedan nuevas rutas migratorias por identificar o incluso por descubrir, en su caso, además de las identificadas por Ayala et al., (2007), dada la complejidad de las pautas migratorias neuronales aquí descritas.

Agrupamiento neuronal y sinaptogénesis. En mamíferos, una vez que llegan a su asentamiento final dentro del sistema nervioso, las células nerviosas se agrupan entre sí con un doble objetivo. Para formar las diferentes estructuras del sistema nervioso (Pinel, 2007), por un lado. Por otro lado, para dar lugar a un primer entramado de conexiones sinápticas -proliferación sináptica-. Éste precederá al futuro complejo de sinapsis respondiente a las demandas ambientales. Se trata del proceso comúnmente denominado como sinaptogénesis. Este proceso consiste en una exuberante sobreproducción de sinapsis (Kalat, 2004) y en una arborización neuronal (Semple et al., 2013) -el desarrollo de las dendritas y espinas dendríticas de las neuronas-. En el ser humano, la sinaptogénesis comienza aproximadamente hacia el final del último trimestre de gestación prenatal (Whitaker-Azmitia, 2010) pero continúa de manera muy pronunciada después del nacimiento. Alcanza su cota máxima a la edad de dos años de edad (Semple et al., 2013).

El objetivo de esta primera red de contactos sinápticos es establecer las bases de una comunicación neuronal eficaz, es decir, que lleve a las neuronas a producir sinapsis correctas. De hecho, la comunicación neuronal durante la sinaptogénesis es una condición clave para el desarrollo funcional normal -libre de alteraciones- del sistema nervioso. Para que se dé esta condición, cada neurona debe recibir axones de las células presinápticas 

adecuadas, y proyectar su axón a las células nerviosas postsinápticas oportunas. Para ello, los axones y dendritas de las neuronas han de seguir desarrollándose. Más concretamente, los axones tienen que crecer lo suficiente como para alcanzar otras neuronas con las que poder establecer contactos sinápticos correctos, y las dendritas tienen que arborizarse con el mismo fin.

Un axón en crecimiento recibe el nombre de neurita, y el crecimiento axónico también es denominado como proceso de elongación neurítica (Rösner, Möller, Wassermann, Mihatsch y Blum, 2007). Lo que favorece este crecimiento axónico es el extremo en crecimiento de un axón, también denominado como cono de crecimiento, descrito por el premio Nobel Ramón y Cajal en 1890 (Ramón y Cajal, 1890). Este cono de crecimiento guía el crecimiento de la neurita hacia las neuronas con las que ha de establecer contactos, extendiendo y retrayendo sus filopodios (Gallo, 2013). Durante su proceso de elongación, la neurita puede sufrir arborización dendrítica (Rösner et al., 2007).

Actualmente, se considera que el cono de crecimiento es dirigido por ciertas señales químicas emitidas por la neurona diana, que regulan el crecimiento neurítico. Se discuten dos hipótesis diferentes acerca del mecanismo químico específico que explicaría este proceso. Por un lado, la hipótesis de la quimo-afinidad postula que los axones en crecimiento se ven atraídos por factores de crecimiento o neurotrofinas liberadas por la neurona objetivo del contacto postsináptico (Cohen y Levy-Montalcini, 1956; Kalat, 2004; Pinel, 2007). La primera y más conocida neurotrofina es el factor de crecimiento del nervio (FCN), descubierta por Cohen y Levy-Montalcini (1956), pero también se encuentran dentro de este grupo el factor neurotrófico derivado del cerebro (Hubka, 2006; Pedersen, Pedersen, Krabbe, Bruunsgaardm, Matthews y Febbraio, 2009; Ascano, Bodmer y Kuruvilla, 2012; Rao, 2013), la neurotrofina-3 (NT-3) y la neurotrofina-4/5 
(NT-4/5) (Mori, Takumi, Shimizu, Oishi y Hayashi, 2006; Ascano et al., 2012). Por otro

lado, la hipótesis de la adhesión molecular postula que las neuritas se adhieren a determinadas proteínas contenidas en el objetivo postsináptico (Rossi, Gianola y Corvetti, 2007; Kim, Bao, Bonanno, Zhang y Serpe, 2012; Kim y Serpe, 2013). Entre las más conocidas, destacan las netrinas, efrinas, semaforinas y slits (Rossi et al., 2007). Es posible que algunos conos de crecimiento se comporten según lo postulado por la primera hipótesis y otros según lo postulado por la segunda. Alternativamente, la acción combinada de ambos mecanismos podría explicar el comportamiento de los conos de crecimiento. Finalmente, sendas hipótesis podrían explicar tal comportamiento en dos fases diferentes de la sinaptogénesis, respectivamente. La primera se referiría a la dirección del cono de crecimiento, y la segunda se ocuparía de la adhesión entre las células pre y postsinápticas en el momento de establecer contactos entre sí (Kim y Serpe, 2013). Interesantemente, se postula también que estas señales químicas facilitan pero también restringen activamente el crecimiento neurítico. Por ejemplo, las semaforinas Sema4D (Moreau-Fauvarque et al., 2003) y Sema5A (Goldberg, 2004) y la efrina B3 (Benson, Romero, Lush, Lu, Henkemeyer y Parada, 2005) inhiben el crecimiento axónico para evitar la formación de circuitos neuronales aberrantes y, por lo tanto, el caos anatómico funcional del sistema nervioso (Rossi et al., 2007).

La formación sináptica del desarrollo del sistema nervioso fue estudiada por primera vez en el cerebro humano por Huttenlocher (1979). Éste demostró que aquélla sigue un curso de desarrollo específico de la edad y de la región cerebral (Semple et al., 2013). En concreto, comienza en el quinto mes de gestación (Rivkin, 2000; Semple et al., 2013); pasa por un rápido crecimiento sináptico durante los primeros meses postnatales y continúa hasta bien entrados los dos años de edad (Huttenlocher, 1979; Herschkowitz, Kagan y Zilles, 1997). Por su parte, Ashwell y Mai (2012) han identificado que la 
sinaptogénesis acontece en primer lugar en regiones subcorticales del cerebro -en el tálamo- y, posteriormente, en regiones superiores del cerebro -corteza prefrontal-. Finalmente, Huttenlocher, De Courten, Garey y Van der Loos (1982) y Lenroot y Giedd (2006) han observado que los picos de máxima densidad sináptica se producen en la corteza visual primaria y en la corteza cerebral prefrontal entre los ocho y doce meses y entre los dos y cuatro años de edad, respectivamente.

Por lo tanto, la sinaptogénesis también sigue un patrón espaciotemporal no simultáneo a lo largo del sistema nervioso humano. En otras especies, como los primates, sin embargo, las primeras conexiones sinápticas se establecen en todas las regiones cerebrales simultáneamente (Capilla González y Pérez Hernández, 2008).

Mielinización. Una vez formados los axones, y sólo en el caso de algunos de ellos, éstos serán recubiertos por una gruesa capa aislante, la vaina de mielina. Existen, pues, fibras mielínicas y fibras amielínicas. Ésta es la causante del aspecto blanco de la materia blanca del sistema nervioso (Ahrens, Blumenthal, Jacobs y Giedd, 2000). Esta sustancia es segregada por las células gliales, principalmente por células de Schwann en el sistema nervioso periférico y por astrocitos, microglía y, en mayor abundancia, por oligodendrocitos en el sistema nervioso central (Su y He, 2010).

Por un lado, las células de Schwann proceden de sus propias células precursoras, originadas, a su vez, a partir de células migratorias de la cresta neural. Los precursores de células de Schwann son aún células inmaduras, es decir, sin definición funcional. Sin embargo, a medida que avanza su desarrollo, se van diferenciando como células de Schwann productoras o no productoras de mielina, respectivamente. Esta diferenciación funcional depende, en última instancia, de señales provenientes de los axones con los que establece contactos cuando las células de Schwann inmaduras se adentran en el sistema nervioso periférico. Las células de Schwann productoras de mielina se diferencian antes 
que las no productoras de mielina (Ndubaku y de Bellard, 2008). Durante el transcurso de su desarrollo, los axones son separados entre sí por las células de Schwann productoras de mielina, estableciendo una relación de ratio 1-1 con los axones a los que pasará a mielinizar progresivamente (Yao, Windenbank, Poduslo y Yoshino, 1990; Ndubaku y de Bellard, 2008).

Por otro lado, los oligodendrocitos derivan de sus precursores que, a su vez, se originan de las células madre neuronales de distintas zonas germinales del tubo neural (Kinameri y Matsuoka, 2003; Rossi et al., 2007; Yang, Lewis y Miller, 2011). Los precursores de oligodendrocitos sufrirán procesos migratorios a través del sistema nervioso central antes de diferenciarse en oligodendrocitos propiamente dichos. Estos precursores celulares pueden generar, además, astrocitos y neuronas (Kondo y Raff, 2004; Ndubaku y de Bellard, 2008; Yang et al., 2011). Una vez que esta diferenciación tiene lugar, y que, por lo tanto, han madurado, los oligodendrocitos comienzan a segregar proteína básica de mielina y otros elementos de la mielina, y, por lo tanto, a formar las vainas compactas de mielina (Yang et al., 2011). Éstas se ven interrumpidas por unas hendiduras -los nodos de Ranvier-, que provocan que el impulso nervioso brinque entre ellos (conducción saltatoria), acelerando, así, su conducción a lo largo de la célula nerviosa (Caldwell, 2009). El número final de oligodendrocitos parece depender de que el linaje celular llegue a un equilibrio determinado (Yang et al., 2011), dado que más precursores de oligodendrocitos no dan lugar a más oligodendrocitos, y que la sobreproducción de oligodendrocitos provoca su muerte celular (Richardson et al., 1988; Calver et al., 1998).

La mielinización del cerebro comienza en la decimosegunda y decimotercera semanas posteriores a la concepción en regiones caudales, y continúa progresivamente durante la infancia, la adolescencia y hasta bien entrada la adultez, en regiones rostrales 
(Girard et al., 2007; Rapopport y Gogtay, 2008). Sigue, por lo tanto, un curso de desarrollo in crescendo y temporal de menor a mayor edad (Rohlfs Domínguez, 2010) y un curso espacial trasero-delantero (Gogtay, 2008). Además, esta mielinización in crescendo tiene lugar generalmente desde regiones cerebrales inferiores, tales como las áreas cerebrales responsables de las funciones sensoriales y motoras, a regiones superiores del cerebro, como las áreas de asociación, por ejemplo, la corteza frontal. Sigue, por lo tanto, un curso espacial inferior-superior (Gogtay et al., 2004; Casey, Galvan y Hare, 2005; Lebel, Walker, Leemans y Beaulieu, 2008).

Finalmente, la mielinización depende de la actividad funcional de los axones (Zatorre, Fields y Johansen-Berg, 2012). Ésta es inducida por las experiencias derivadas del ambiente (Ishibashi, Dakin, Stevens, Lee, Kozlov, Stewart et al., 2006), incluidas las experiencias sociales (Liu et al., 2012; Makinodan, Rosen, Ito y Corfas, 2012), de la comunicación entre neuronas y células gliales (Fields, 2004; Almeida y Lyons, 2014) y del contacto entre neuronas y ciertas moléculas de adhesión (Comana, Barbina, Charlesa, Zalca y Lubetzki, 2005). Estos dos últimos factores también dependen de la actividad axonal. A más actividad funcional axonal, más mielinización y, por lo tanto, más fortalecimiento de las conexiones sinápticas implicadas (Nordeen y Nordeen, 2004). Este tipo de fortalecimiento de las conexiones sinápticas se refleja especialmente en los conocidos "períodos sensibles" de aprendizaje de muchas conductas (Nordeen y Nordeen, 2004) y de desarrollo sensorial y probablemente cognitivo. Se trata de períodos en los que resulta especialmente sencillo aprender la ejecución de una conducta, por ejemplo, aprender a hablar un primer -a los dos años- y segundo idiomas -a los dos cuatro- (Giraud y Lee, 2007). Además, de darse la estimulación adecuada, las funciones sensoriales, por ejemplo, la visión (Lewis y Maurer, 2005), se desarrollan mejor. 


\section{Reorganización neuronal: mantenimiento de las conexiones establecidas versus}

apoptosis y poda sináptica. De la sobreproducción de neuronas y conexiones neuronales generada, algunas sobrevivirán mientras que otras, las sobrantes (Maor-Nof y Yaron, 2013), serán eliminadas mediante procesos selectivos de autodestrucción letal. En el caso de las neuronas, este proceso se llama apoptosis o muerte celular programada. En el caso de las sinapsis, nos referimos a la poda sináptica, eliminación sináptica o poda axónica.

La apoptosis neuronal, por un lado, consiste en la desintegración de las neuronas en partículas (Lüer y Technau, 2009), y suele ocurrir al final de la gestación (Aswell y Mai, 2012). No obstante, también se ha constatado durante el primer trimestre de gestación (Rakic y Zecevic, 2000) y entre el tercer trimestre de desarrollo prenatal y el sexto mes postnatal (Kostovic et al., 1989; Kostovic y Rakic, 1990; Marin-Padilla, 1997). Sin embargo, también puede afectar a células gliales (Winseck et al., 2002; Lossi et al., 2005). Hasta la mitad de las células originalmente producidas se pueden perder mediante este proceso de desarrollo (Becker y Bonni, 2004; Yeo y Gautier, 2004).

El proceso de apoptosis es comúnmente denominado como muerte celular programada, debido a que cursa a través de toda una compleja serie de eventos predeciblemente regulados durante el desarrollo del sistema nervioso. También recibe el nombre de muerte neuronal natural. Además, como son las propias células las responsables de su propia desaparición, la muerte celular programada suele considerarse como una especie de suicidio celular. No obstante, la muerte celular programada puede ser causada por trastornos neurodegenerativos como el Alzheimer (Jiménez del Río y Vélez Pardo, 2001), o por agentes físicos y químicos varios, e incluso ha sido asociada al envejecimiento (Lossi et al., 2005).

Se postula que se trata de un proceso necesario, evolucionado para corregir circunstancias que podrían causar daños mortales en el embrión (Buss, Sun y Oppenheim, 
2006). Su función principal sería la de ajustar el número de neuronas del sistema nervioso central y del sistema nervioso periférico para proporcionar suficiente inervación tanto a los centros neurales, diana de sus eferencias, como a los centros neurales desde los que recibe aferencias (Becker y Bonni, 2004; Buss et al., 2006). La muerte celular programada corrige también errores en la formación de las conexiones sinápticas. Por último, regula el número de precursores celulares en zonas germinales del sistema nervioso central y del sistema nervioso periférico, que, a su vez, regulan el tamaño y la morfología de las estructuras neuronales resultantes (Buss et al., 2006). De hecho, se ha constatado muerte celular programada en la ZV, coincidiendo con el comienzo de la neurogénesis, y, por lo tanto, en una fase muy temprana del desarrollo neural, en varias especies de vertebrados, incluidos mamíferos como el ratón (Yeo y Gautier, 2004). En el ser humano también se ha encontrado muerte celular programada en las zonas proliferativas del telencéfalo (De Graaf-Peters y Hadders-Algra, 2006). Sin embargo, esta temprana muerte celular programada (Yeo y Gautier, 2004) no está relacionada con la formación sináptica (Lossi y Merighi, 2003).

Por otro lado, la poda axónica tiene lugar, durante el desarrollo postnatal del sistema nervioso (Rivkin, 2002; Aswell y Mai, 2012), a consecuencia de la muerte celular programada (Saxena y Caroni, 2007). Si bien, otros factores, tales como lesiones y/o trastornos del sistema nervioso, pueden causar igualmente poda axónica (Saxena y Caroni, 2007). Los mecanismos de poda axónica más conocidos son la retracción de los axones, por un lado, y la degeneración de los mismos, por otro lado (Kantor y Kolodkin, 2003; Saxena y Caroni, 2007). En la retracción axónica, el axón es retraído gradualmente hacia atrás, de tal manera que su material es trasladado a secciones proximales del axón (Saxena y Caroni, 2007). En la degeneración, en cambio, los axones sufren pérdidas de fragmentos ricos en material sináptico, denominados axosomas (Koirala y Chien-Ping, 
2004), término introducido por el laboratorio de Jeff Lichtman (Bishop, Misgeld, Walsh,

Gan y Lichtman, 2004), que luego son fagocitados por glia adyacente (Saxena y Caroni, 2007), por ejemplo, células de Schwann (Bishop et al., 2004; Koirala y Chien-Ping, 2004; Maor-Nof, M. y Yaron, 2013). En cualquier caso, en el ser humano se ha constatado poda sináptica durante la infancia (entre los seis meses postnatales y los siete años de edad) (Huttenlocher, 1979). Asimismo, se ha encontrado pérdida de materia gris (de somas y dendritas) en la adolescencia, atribuyéndose a poda axónica (Gogate, Giedd, Janson y Rapoport, 2001; Sowell, Thompson, Tessner y Toga, 2001; Blakemore y Choudhury, 2006; Blakemore, 2012). Dado que también se han encontrado pérdidas masivas de materia gris entre los veinte y treinta años de edad en la corteza frontal (Sowell et al., 2001; Sowell, Peterson, Thompson, Welcome, Henkenius y Toga, 2003), sería plausible que procesos de poda sináptica tuvieran lugar también durante la adultez temprana, lo que habría que dilucidar en un futuro. Otros autores, sin embargo, atribuyen dichas pérdidas de materia gris a cambios en la distribución entre la materia gris y blanca (Lu et al., 2007; Sowell et al., 2003; Casey et al., 2005; Rapoport y Gogtay, 2008). Es posible que la combinación de sendos procesos de desarrollo determinen tales pérdidas (Rohlfs Domínguez, 2011). En cualquier caso, resulta lógico asumir que la poda sináptica también es un proceso cuyo curso de desarrollo depende de la edad del individuo y de la región cerebral.

La eliminación o supervivencia de neuronas y conexiones nerviosas relacionadas con la formación sináptica, que es diferente de la muerte celular programada temprana (Yeo y Gautier, 2004), depende de la competición neuronal por los llamados factores neurotrópicos, tales como el FCN (Buss et al., 2006). Estos estimulan la supervivencia y la actividad de la neurona, así como la sinaptogénesis. De hecho, la premio Nobel de 1986 en fisiología y medicina Levy-Montalcini, junto con Cohen, descubrió que aquellos axones que no recibían suficiente FCN degeneraban, y sus somas morían. Un axón recibe 
suficiente FCN para sobrevivir estableciendo contactos exitosos con otras neuronas, de las cuales reciben esta sustancia. Durante el desarrollo, si un axón no establece el contacto correcto con una neurona a una determinada edad, la neurona muere (apoptosis). Cuando las neuronas y/o axones son eliminados, los espacios vacantes son ocupados por nuevos axones y ramificaciones dendríticas desarrolladas por las neuronas supervivientes, dando lugar a una reorganización masiva de las conexiones nerviosas (Pinel, 2007; Saxena y Caroni, 2007). Los mecanismos específicos de esta reocupación neuronal y reorganización sináptica están aún por esclarecerse.

En los vertebrados, la experiencia (medio ambiente externo), a demás de la genética (medio ambiente interno), resulta ser crucial en el mantenimiento y/o eliminación de conexiones nerviosas. Se trata de la modulación ambiental del desarrollo ontogenético (embrionario-fetal) del sistema nervioso. Las neuronas y sinapsis que no son activadas por la experiencia derivada del medio ambiente externo normalmente no sobreviven. Esta sencilla regla cobra especial importancia en lo concerniente a los períodos sensibles de aprendizaje conductual y de desarrollo sensorial y probablemente cognitivo. En estos períodos, el aprendizaje de determinadas conductas, así como el desarrollo de funciones sensoriales y probablemente cognitivas no será viable si las conexiones sinápticas que las posibilitan se han eliminado mediante poda axónica. Esto, a su vez, da lugar a una alteración del desarrollo del individuo. Por lo tanto, la poda axónica es un proceso de desarrollo que tiene un papel protagonista fundamental en la regulación de la plasticidad neural. La plasticidad neural se puede definir como la capacidad del cerebro de reorganizar su morfología y función en base a las experiencias con el medio externo (Rohlfs Domínguez, 2010).

Durante la vida de un individuo, los procesos de formación y eliminación sináptica se intercalan intermitentemente, dando lugar a una continua reorganización de los 
circuitos neuronales que supone la base de la plasticidad neuronal (De Graaf-Peters y Hadders-Algra, 2006).

Como se puede apreciar, la secuencia de eventos ontogenéticos del desarrollo prenatal del sistema nervioso humano se desarrolla a través de dos fases consecutivas. La primera tiene lugar a partir de la fecundación y la segunda afecta al período embrionariofetal. La Tabla 1 recoge una síntesis de los eventos que nos ocupan.

Tabla 1

Secuencia de eventos ontogenéticos implicados en el desarrollo del sistema nervioso humano

\begin{tabular}{|c|c|}
\hline Evento ontogenético & Fase de desarrollo \\
\hline Gastrulación (emergencia del ectodermo) & $1^{\mathrm{a}}, 3$ días post fecundación \\
\hline $\begin{array}{c}\text { Emergencia de la placa nural o } \\
\text { neuroectodermo }\end{array}$ & $2^{\mathrm{a}}, 2$ semanas días \\
\hline Neurulación primaria & $2^{\mathrm{a}}, 4$ semanas \\
\hline Neurogénesis & $2^{\mathrm{a}}, 3$ Meses \\
\hline Migración neuronal & $2^{\mathrm{a}} 3-5$ Meses \\
\hline Sinaptogénesis & $\begin{array}{c}2^{\mathrm{a}}, \text { Final del Tercer trimestre de } \\
\text { gestación-Dos años }\end{array}$ \\
\hline Mielinización & $\begin{array}{c}2^{\mathrm{a}}, 12^{\mathrm{a}} \text { semana post concepción-vida } \\
\text { adulta }\end{array}$ \\
\hline Apoptosis & $\begin{array}{l}2^{\mathrm{a}} \text {, Final de la gestación prenatal- } 6^{\mathrm{o}} \text { mes } \\
\text { postnatal }\end{array}$ \\
\hline Poda axónica & Desarrollo postnatal \\
\hline
\end{tabular}

Este trabajo se ha elaborado fundamentalmente con el objetivo de dilucidar el estado actual del conocimiento sobre la secuencia de eventos ontogenéticos implicados en el desarrollo prenatal del sistema nervioso humano y sobre los propios eventos. Además, pretende contribuir, de manera didáctica, a la introducción del público lector en los elementos más fundamentales de tal secuencia de eventos. De acuerdo con estos objetivos, se ha elaborado desde una perspectiva general. Para ello, se ha basado 
principalmente en trabajos de investigación humana y animal llevados a cabo por la comunidad científica nacional e internacional durante los últimos diez años. Este trabajo también es fruto del esfuerzo investigador que la autora ha invertido, como profesora de la asignatura Psicobiología del Desarrollo en los respectivos departamentos de Psicobiología de la Universidad de Granada, la Universidad de Huelva (España) y la Universidad de Potsdam (Alemania), en la temática aquí discutida, durante los penúltimos cursos académicos. Por lo tanto, se trata de una monografía actualizada hasta 2013.

El presente trabajo supone una contribución científica que, dado su carácter actualizador en relación al conocimiento aquí vertido, puede inspirar en el futuro a otros autores, por ejemplo, de cara a generar nuevas hipótesis de estudio en relación a desarrollo del sistema nervioso humano. Por otro lado, este trabajo pretende ser una herramienta útil en el estudio e impartición de asignaturas como Psicobiología del Desarrollo y otras materias relacionadas con ésta.

\section{Discusión}

A continuación, se discuten las evidencias identificadas respecto del estado actual del conocimiento sobre la secuencia de los distintos eventos ontogenéticos implicados en el desarrollo prenatal del sistema nervioso humano y sobre aquéllos.

En relación a la secuencia de tales eventos, conviene destacar aquí que, de la literatura aquí revisada, se deduce que existe acuerdo en la comunidad científica en que existen dos fases claramente diferenciadas. La primera atañe al óvulo fertilizado o zigoto y la segunda al embrión y feto.

Sobre la primera, también existe acuerdo en afirmar que el evento ontogenético implicado en el desarrollo prenatal del sistema nervioso humano es la sucesiva transformación del zigoto, mediante división celular mitótica, en tres estados diferentes mórula, blástula y gástrula-. Es en este último estado cuando aparece la capa celular que 
decir, la capa celular conformada por progenitores de las células que en un futuro configurarán el sistema nervioso humano. Por lo tanto, la emergencia de la gástrula supone un punto de inflexión a la hora de determinar el origen del sistema nervioso humano. En este sentido, se aprecia, tal y como afirma (Mancheño Maciá y Giménez Ribotta, 2005), la progresiva especialización funcional de las células que conforman el zigoto. De hecho, éstas pasan de ser células madre totipotenciales -en la fase de mórulaa células multipotenciales -en la fase blástula- y, finalmente, a progenitores -en la fase de gástrula-.

En cuanto a la segunda fase, cuando ya el zigoto se ha transformado en embrión, la literatura revisada describe casi unánimemente la ocurrencia de los siguientes hitos biológicos: neurulación primaria; neurogénesis; migración neuronal; agrupamiento neuronal; sinaptogénesis; mielinización y apoptosis. La poda sináptica es un proceso mayormente postnatal.

Acerca de la neurulación primaria, se recuerda aquí que se compone, a su vez, de los siguientes procesos ontogenéticos: fusión de los pliegues neurales de la placa neural; desarrollo de la cresta neural; formación del tubo neural y migración celular de la cresta neural. Es precisamente este último acontecimiento el que suscita cierto debate científico; mientras que algunos autores -Huang y Saint-Jeannet (2004); Sadler, (2009); Betters, Liu, et al., 2010- sitúan esta migración celular, en el caso del ser humano y del ratón, una vez conformada la cresta neural, otros autores -Milet y Monsoro-Burg (2012)- la localizan ya en la fase de gastrulación, en el caso de la rana. Por otra parte, la completa formación del tubo neural supone otro punto de inflexión en el desarrollo prenatal del sistema nervioso humano, dado que, siguiendo a Lim y Glden (2007), determina las dos grandes divisiones del sistema nervioso central -cerebro y médula espinal-. 
Con respecto a la proliferación neuronal o neurogénesis, la mayoría de autores la sitúan en la ZV y ZSV, y afirman que las neuronas aquí producidas derivan directamente de precursores neuronales cuyos nichos se encuentran precisamente en sendas zonas (Cavada, 1988; Parnavelas, 2000; Kriegstein y Noctor, 2004; De Graaf-Peters y HaddersAlgra, 2006; Ayala et al., 2007; Snell, 2007). Sin embargo, un brillante trabajo de revisión (Kriegstein y Álvarez-Buylla, 2009) ha identificado que las células madre gliales radiales situadas en estas zonas también pueden generar precursores neuronales e incluso neuronas. Esto supone evidencia en contra de una total diferenciación estructural y funcional entre células neuronales y gliales. Otro dato interesante a destacar aquí es que la producción de células en la cresta neural está comúnmente asociada a la formación del futuro sistema nervioso periférico (Dickinson et al., 2004; Kiernan y Rajakumar, 2013; Hao et al., 2013). Sin embargo, otros autores -Le Douarin y Dupin, 2003; Milet y Monsoro-Burg, 2012- han identificado la capacidad de las células de la cresta neural de generar células de otros tipos, tales como el óseo o tendinoso. Por lo tanto, y dadas estas evidencias, se puede afirmar que las células de la cresta neural están dotadas de multipotencialidad. Finalmente, cabe mencionar que la literatura aquí revisada refleja también acuerdo en considerar que el curso espaciotemporal de la generación de neuronas a lo largo del sistema nervioso no es simultáneo. Una de las evidencias más claras al respecto es la ya tan comprobada neurogénesis adulta por autores como Arias-Carrión et al., (2007); Cayre et al., (2009); Lossi et al., (2009) y Belvindrah et al., (2011), entre otros.

En cuanto a la migración neuronal, se aceptan comúnmente tanto la migración tangencial (Ayala et al. 2007) como la radial (por ejemplo, Marin y Rubenstein, 2003) como los dos tipos de migración neuronal conocidos, así como dos métodos de locomoción utilizados por las neuronas durante la mencionada migración -el cambio de localización del soma y el mediado por neuroglia (Hatten 2002; Ayala et al., 2007; Pinel, 
2007). Sin embargo, los indicios que apuntan a que algunas neuronas cambian de dirección durante su viaje migratorio (Parnavelas, 2000; Pinel, 2007; Métin et al., 2008) lleva a cuestionar la clasificación de las neuronas como neuronas migratorias tangenciales y como neuronas migratorias radiales como vigente.

Sobre la sinaptogénesis, se puede afirmar que toda una serie de evidencias proporcionadas por la literatura aquí revisada (Huttenlocher et al., 1982; Lenroot y Giedd, 2006; Capilla González y Pérez Hernández, 2008; Ashwell y Mai, 2012) indican que la sinaptogénesis tiene lugar de menor a mayor edad y de zonas inferiores del cerebro a zonas superiores del mismo. Esto revalid lo ya aportado por Huttenlocher en la década de los setenta, esto es, que la sinaptogénesis prenatal humana sigue un patrón de desarrollo dependiente de la edad y de la región del cerebro, y que éste un patrón específico del ser humano. Otro conjunto de evidencias señala al crecimiento neurítico como factor sine qua non para que la sinaptogénesis pueda tener lugar. El mecanismo que lo facilita, en cambio, se debate actualmente. Mientras que algunos autores apuestan por la hipótesis de la quimo-afinidad (Cohen y Levy-Montalcini, 1956; Kalat, 2004; Pinel, 2007), otros defienden la de la adhesión molecular (Rossi et al., 2007; Kim et al., 2012; Kim y Serpe, 2013). Aquí se propone la hipótesis de que ambos mecanismos pueden explicar el crecimiento neurítico, pero hay que someterla a verificación en el futuro.

Por otro lado, la evidencia recogida en este trabajo acerca de la mielinización destaca su dependencia de la actividad de los axones inducida por la experiencia externa (Nordeen y Nordeen, 2004; Zatorre et al., 2012). Asimismo, la procedencia de la vaina de mielina, principalmente de células de Schwann en el sistema nervioso periférico y de astrocitos, microglía y, en mayor abundancia, oligodendrocitos en el sistema nervioso central (Su y He, 2010) también queda aquí destacada. 
Finalmente, y con respecto a la apoptosis, el último evento ontogenético del desarrollo prenatal del sistema nervioso humano, cabe decir que aunque está asociada al final de la gestación prenatal, tal y como han identificado Aswell y Mai (2012), también se ha constatado durante el primer trimestre de gestación (Rakic y Zecevic, 2000) y entre el tercer trimestre de desarrollo prenatal y el sexto mes postnatal (Kostovic et al., 1989; Kostovic y Rakic, 1990; Marin-Padilla, 1997).

\section{Conclusiones}

El presente trabajo de investigación se ha elaborado fundamentalmente con el objetivo de presentar una actualización acerca del conocimiento producido hasta el año 2013 sobre la secuencia de eventos ontogenéticos involucrados en el desarrollo prenatal del sistema nervioso humano y sobre estos eventos.

A la luz de la presente monografía, se puede concluir, en primer lugar, que, en relación a la secuencia de los eventos que nos ocupan, existen dos fases bien diferenciadas, una que comienza nada más se ha producido la fecundación y una segunda fase que abarca el desarrollo embrionario-fetal del futuro individuo. En ambas fases se constata la ocurrencia de toda una serie de eventos ontogenéticos -sintetizados en la tabla 1-, necesarios para el buen desarrollo del sistema nervioso humano.

La segunda conclusión se refiere al hecho de que, mientras que algunos de los eventos ontogenéticos del desarrollo embrionario-fetal del sistema nervioso humano aquí descritos transcurren sucesivamente, otros se solapan entre sí. Por ejemplo, la sinaptogénesis ocurre concurrentemente con el crecimiento axonal y dendrítico y con la mielinización. Tal solapamiento de eventos sugiere que el desarrollo embrionario-fetal del sistema nervioso humano acontece a lo largo de un continuo espaciotemporal que sigue un curso constante y sin interrupción. Sin embargo, no todos los eventos de desarrollo prenatal descritos ocurren por igual y simultáneamente en todo el sistema 
nervioso. De hecho, el desarrollo prenatal del sistema nervioso sigue un orden espaciotemporal relativamente establecido y sometido a la edad del individuo y a la región cerebral específica. Mientras que las regiones inferiores (sensoriales y motoras) se desarrollan tempranamente y, por lo tanto, en individuos jóvenes, las regiones superiores (de asociación) se desarrollan con posterioridad y en individuos más avanzados en edad. Además, este patrón de desarrollo ontogenético del sistema nervioso coincide con su patrón desarrollo evolutivo, en tanto que las regiones inferiores son, filogenéticamente hablando, más antiguas que las superiores, que emergieron más tardíamente. El curso de desarrollo embrionario-fetal del sistema nervioso humano muestra, por lo tanto, un patrón indiscutiblemente estereotipado. Por otra parte, el desarrollo prenatal del sistema nervioso humano se ve influido por las influencias del ambiente externo (experiencia), además de por la de los propios genes, hecho que tampoco suscita debate científico.

En tercer lugar, cabe afirmar que el desarrollo prenatal del sistema nervioso implica la emergencia y el desarrollo paralelo, tanto de estructuras anatómicas como de funciones. La alteración de este proceso puede provocar alteraciones anatómicas y funcionales perjudiciales para el individuo. De aquí que el desarrollo prenatal del sistema nervioso humano cuente con mecanismos como la apoptosis destinada a la corrección de de errores en la formación de conexiones sinápticas durante la sinaptogénesis.

La presente monografía tiene varias implicaciones. Por un lado, presenta el estado actual de los eventos ontogenéticos del desarrollo prenatal del sistema nervioso humano y su secuencia hasta 2013, lo que lleva a una mejor comprensión de los mismos. Por otro lado, identifica una serie de interrogantes que convendría dilucidar en el futuro, y que se muestran más abajo.

En cuanto a las limitaciones de esta monografía, cabe decir que ésta incluye el tratamiento de la secuencia total de eventos ontogenéticos. Por esta razón, está elaborada 
desde una perspectiva general. Futuros trabajos de investigación, por ejemplo, de revisión de tipo Cochrane (The Cochrane Collaboration, 2013) podrían concentrarse de manera más específica y profunda en cualquiera de los eventos ontogenétgicos aquí descritos.

Finalmente, se exponen a continuación varias recomendaciones para futuras investigaciones. Estas recomendaciones están destinadas a resolver en el futuro las siguientes cuestiones por medio de esfuerzo investigador para comprender mejor la ocurrencia y curso de los eventos ontogenéticos que aquí nos ocupan.

En relación a la migración neuronal, surgen las siguientes preguntas de investigación: ¿Podría existir migración celular en humanos ya en la fase de gastrulación? ¿Cumple la migración celular en cada una de estas localizaciones funciones diferenciadas? Dar respuesta a estas preguntas es especialmente interesante, puesto que la migración neural supone un punto de inflexión en el desarrollo prenatal del sistema nervioso humano, ya que está implicada en el desarrollo del futuro sistema nervioso periférico. Además, se desconoce la influencia que tiene la variable velocidad de la migración neuronal en el desarrollo del sistema nervioso ni las consecuencias que pudieran derivarse de alteraciones de esta variable. Se desconoce también si las neuronas de patrón migratorio tangencial pueden cambiar su forma celular y su velocidad y dirección de migración, como sí lo hacen las neuronas de patrón migratorio radial. Tampoco se sabe si existen más rutas migratorias de las ya identificadas ni cuáles son.

La comprensión de la sinaptogénesis tampoco está exenta de nuevas preguntas de investigación. En concreto, se recomienda responder a las preguntas ¿qué tipo de conos de crecimiento se comportan según la hipótesis de la quimo-afinidad y qué tipo de conos hacen lo propio según la hipótesis de la adhesión molecular? ¿podrían explicar sendas hipótesis el comportamiento de los conos de crecimiento en fases diferentes de la sinaptogénesis? 
Finalmente, en base a la literatura aquí revisada acerca de la poda sináptica, surge la pregunta de si existe poda sináptica durante la adultez temprana. 


\section{Referencias}

Ahrens, E.T., Blumenthal, J., Jacobs, R.E., y Giedd, J.N. (2000). Imaging Brain Development. En A.W. Toga, y J.C. Mazziota (Eds.), Brain mapping: the systems (pp.561-589). San Diego: Academic Press.

Almeida, R.G., y Lyons, D.A. (2014). On the resemblance of synapse formation and CNS myelination. Neuroscience, 276, 98-108. doi: 10.1016/j.neuroscience.2013.08.062.

Arias-Carrión, O., Olivares-Bañuelos, T., y Drucker-Colín R. (2007). Neurogénesis en el cerebro adulto. Revista de Neurología, 44(9), 541-50.

Ascano, M., Bodmer, D., y Kuruvilla, R. (2012). Endocytic trafficking of neurotrophins in neural development. Trends in Cell Biology, 22(5), 266-273. doi: 10.1016/j.tcb.2012.02.005.

Ashwell, K.W.S. y Mai, J.K. (2012). Fetal development of the central nervous system. En J.K. Mai y G. Paxinos (Eds.). The human nervous system (pp. 31-79). San Diego: Elsevier. doi: 10.1016/B978-0-12-374236-0.10003-3.

Ayala, R., Shu, T., y Tsai, L.H. (2007). Trekking across the brain: the journey of neuronal migration. Cell, 12(1), 29-43.

Beane, W.S., Gross, J.M., y McClay, D.R. (2006). RhoA regulates initiation of invagination, but not convergent extension, during sea urchin gastrulation. Developmental Biology, 292(1), 213-225.

Bédard, A., y Parent, A. (2004). Evidence of newly generated neurons in the human olfactory bulb. Developmental Brain Research, 151(1-2), 159-168.

Becker, E.B.E., y Bonni A. (2004). Cell cycle regulation of neuronal apoptosis in development and disease. Progress in Neurobiology, 72(1), 1-25.

Beltz, B.S., y Sandeman, D.C. (2003). Regulation of life-long neurogenesis in the 

decapod crustacean brain. Arthropod Structure and Development, 32(1), 39-60.

Belvindrah, R., Nissant, A., y Lledo, P.M. (2011). Abnormal neuronal migration changes the fate of developing neurons in the postnatal olfactory bulb. Journal of Neuroscience, 31(20), 7551-7562. doi: 10.1523/JNEUROSCI.6716-10.2011.

Benson, M.D., Romero, M.I., Lush, M.L., Lu, Q.R., Henkemeyer, M., y Parada, L.F. (2005). Ephrin-B3 is a myelin-based inhibitor of neurite outgrowth. Proceedings of the National Academy of Sciences of the United States of America, 102(30), 10694-10699.

Betters, E., Liu, Y., Kjaeldgaard, A., Sunström, E., y García-Castro, M.I. (2010). Analysis of early human neural crest development. Developmental Biology, 344(2), 578-592. doi: 10.1016/j.ydbio.2010.05.012.

Bishop, D.L., Misgeld, T., Walsh, M.K., Gan, W.B., y Lichtman, J.W. (2004). Axon branch removal at developing synapses by axosome shedding. Neuron, 44(4), $651-661$.

Blakemore, S.J. y Choudhury S. (2006). Development of the adolescent brain: implications for executive function and social cognition. Journal of Child Psychology and Psychiatry, 2006; 47: 296-312.

Blakemore, S.J. (2012). Imaging brain development: the adolescent brain. Neuroimage, 61(2), 397-406.

Buss, R.R., Sun, W., y Oppenheim RW. (2006). Adaptative roles of programmed cell death during nervous system development. Annual Review Neuroscience, 29, 135.

Caldwell, J.H. (2009). Action potential initiation and conduction in axons. En L.R. Squire (Ed.), The encyclopedia of neuroscience (pp. 23-29). San Diego: Academic Press. 
Calver, A.R., Hall, A.C., Yu, W.P., Walsh, F.S., Heath, J.K., Betsholtz C., et al. (1998)

Oligodendrocyte population dynamics and the role of PDGF in vivo. Neuron, 20(5), 869-882.

Capilla González, A., y Pérez Hernández E. Desarrollo cerebral y cognitivo (2008). En

F. Maestú Uturbe, M. Ríos Lago, y R. Cabestrero (Eds.). Neuroimagen: técnicas y procesos cognitivos (pp. 469-490). Barcelona: Elsevier Doyma, S.L.

Casey, B.C., Galvan, A., y Hare TA (2005). Changes in cerebral functional organization during cognitive development. Current Opinion in Neurobiology,15(2), 239-244.

Cavada, C. (1998). Desarrollo del sistema nervioso central. En S. Segovia, y A.

Guillamón (Eds.), Psicobiología del desarrollo (pp. 17-30). Barcelona: Ariel, S.A.

Cayre, M., Canoll, P., y Godman, J.E. (2009). Cell migration in the normal and pathological postnatal mammalian brain. Progress in Neurobiology, 88(1), 41-63. doi: 10.1016/j.pneurobio.2009.02.001.

Chuva de Sousa Lopes, S.M. y Mummery, Ch.L. (2009). Differentiation in Early Development. En R. Lanza, J. Gearhart, B. Hogan, D. Melton, R. Pedersen, E. Donnall Thomas, J. Thompson y L. Wilmut (Eds.). Essentials of Stem Cell Biology. San Diego: Academic Press.

Cohen, S., y Levy-Montalcini, R. (1956). A nerve growth-stimulating factor isolated from snake venom. Proceedings of the National Academy of Sciences of the United States of America, 42(9), 571-574.

Comana, I., Barbina, G., Charlesa, P., Zalc, B., y Lubetzki, C. (2005). Axonal signals in central nervous system myelination, demyelination and remyelination. Journal of Neurological Sciences, 233(1-2), 67-71.

Corr, P.J. (2008). Psicología biológica. México, DF: McGraw-Hill Interamericana. 
Cheng, X., Tiyaboonchai, A., y Gaude, P. (2013). Endodermal stem cell populations derived from pluripotent stem cells. Current Opinion in Cell Biology, 25(2), 2 $65-271$.

De Graaf-Peters, V.B., y Hadders-Algra M. (2006). Ontogeny of the human central nervous system: What is happening when? Early Human Development, 82(4), 257-266.

Dickinson, D.P., Machnicki, M., Ali, M.M., Zhang, Z., y Sohal GS. (2004). Ventrally emigrating neural tube (VENT) cells: a second neural tube-derived cell population. Journal of Anatomy, 205(2), 79-98.

Dicou, E. (2009). Neurotrophins and neuronal migration in the developing rodent brain. Brain Research Reviews, 60(2), 408-417. doi: 10.1016/j.brainresrev.2009.03.001.

Fields, R.D. (2004). Volume transmission in activity-dependent regulation of myelinating glia. Neurochemistry International, 45(4), 503-509.

Gallo, G. (2013). Mechanisms underlying the initiation and dynamics of neuronal filopodia: from neurite formation to synaptogenesis. International Review of Cell and Mololecular Biology, 301, 95-156. doi: 10.1016/B978-0-12-407704-1.00003-8.

Girard, N., Confort-Gouny, S., Schneider, J., Barberet, M., Chapon, F., Viola, A., et al. (2007). MR imaging of brain maturation. Journal of Neuroradiology, 34(5), 290310.

Giraud, A.L., y Lee HJ. (2007). Predicting cochlear implant outcome from brain organisation in the deaf. Restorative Neurology and Neuroscience, 25(3-4), 1-9.

Gogate, N., Giedd, J., Janson, K., y Rapoport JL. (2001). Brain imaging in normal and abnormal brain development: new perspectives for child psychiatry. Clinical Neuroscience Research, 1(4), 283-290. doi:10.1016/S1566-2772(01)00014-7. 
Gogtay, N. (2008). Cortical brain development in schizophrenia: insights from

neuroimaging studies in childhood-onset schizophrenia. Schizophrenia Bulletin, 34(1), 30-36. doi:10.1093/schbul/sbm103.

Gogtay, N., Giedd,. J.N., Lusk, L., Hayashi, K.M., Greenstein, D., y Catherine Vaituzis, A, et al. (2004). Dynamic mapping of human cortical development during childhood through early adulthood. Proceedings of the National Academy of Sciences of the United States of America, 101(21), 8174-9179. doi: 10.1073/pnas.0402680101.

Goldberg, J.L. (2004). Intrinsic neuronal regulation of axon and dendrite growth. Current Opinion in Neurobiology, 14(5), 551-557.

Gupton, S.L., y Waterman-Storer CM. (2006). Spatiotemporal feedback between actomyosin and focal-adhesion systems optimizes rapid cell migration. Cell, 125(7), 1223-1225.

Hao, M.M., Bornstein, J.C., Vanden Berghe, P., Lomax, A.E., Young, H.M. y Foong, J.P.P. (2013). The emergence of neural activity and its role in the development of the enteric nervous system. Developmental Biology, 382(1), 365-74. doi: 10.1016/j.ydbio.2012.12.006.

Hardin, J. (2005a). Echinoderms-Cleavage. Introduction. URL: http://worms.zoology.wisc.edu/dd2/echino/cleavage/intro.html [28.06.2013].

Hardin, J. (2005b). Echinoderms - Gastrulation. Introduction. URL: http://worms.zoology.wisc.edu/dd2/echino/gast/intro.html [28.06.2013].

Huttenlocher, P.R. (1979). Synaptic density in human frontal cortex-developmental changes and effects of aging. Brain Research, 163(2), 195-205. doi:10.1016/0006-8993(79)90349-4.

Hatten, M.E. (2002). New Directions in neuronal migration. Science, 297(5587), 1660- 
1663.

Herschkowitz, N., Kagan, J., y Zilles K. (1997). Neurobiological bases of behavioral development in the first year. Neuropediatrics, 28(6), 296-306.

Hill, MA. Stage 11 sem21.jpg. 2013a. URL:

http://php.med.unsw.edu.au/embryology/index.php?title=Stage11_sem21.jpg [08.07.2013].

Hill MA. Stage 13 sem1c.jpg. 2013b. URL:

http://php.med.unsw.edu.au/embryology/index.php?title=Stage13_sem1.jpg [08.07.2013].

Huang, X., y Saint-Jeannet, J.P. (2004). Induction of the neural crest and the opportunities of life on the edge. Developmental Biology, 275(1), 1-11.

Hubka, P. (2006). Neural network plasticity, BDNF and behavioral interventions in Alzheimer's disease. Bratislava Medical Journal, 107(9-10), 395-401.

Huttenlocher, P.R. (1979). Synaptic density in human frontal cortex - developmental changes and effects of aging. Brain Research, 163(2), 195-205. doi:10.1016/0006-8993(79)90349-4.

Huttenlocher, P.R., De Courten, C., Garey, L.J., y Van der Loos H. (1982).

Synaptogenesis in human visual cortex: evidence for synapse elimination during normal development. Neuroscience Letters, 33(3), 247-252. doi:10.1016/03043940(82)90379-2.

Ishibashi, T., Dakin, K.A., Stevens, B., Lee, P.R., Kozlov, S.V., Stewart, C.L., y Fields, R.D. (2006). Astrocytes promote myelination in response to electrical impulses. Neuron, 49(6), 823-832.

Jiménez del Río, M., y Vélez Pardo, C. (2001). La apoptosis en las enfermedades 

neurodegenerativas: evidencias y controversias. Revista de Neurología, 32(9), 851-860.

Kalat, J.W. (2004). Psicología biológica. Madrid: Wadsworth.

Kantor, D.B., y Kolodkin, A.L. (2003). Curbing the excesses of youth: molecular insights into axonal pruning. Neuron, 38(6), 849-852. doi:10.1016/S08966273(03)00364-7.

Kiernan, J.A., y Rajakumar, R.B. (2013). The human nervous system. An anatomical viewpoint. Baltimore: Lippincott Williams y Wilkins.

Kim, Y.J., Bao, H., Bonanno, L., Zhang, B. y, Serpe M. (2012). Drosophila Neto is essential for clustering glutamate receptors at the neuromuscular junction. Gene Development, 26(9), 974-987. doi: 10.1101/gad.185165.111.

Kim, Y.J., y Serpe, M. (2013). Building a synapse: a complex matter. Fly (Austin), 7(3), 1-7. doi: 10.4161/fly.24413.

Kinameri, E., y Matsuoka I. (2003). Autocrine action of BMP2 regulates expression of GDNF-mRNA in sciatic Schwann cells. Brain research. Molecular brain research, 117(2), 221-227.

Koirala, S., y Chien-Ping, P. (2004). Pruning an axon piece by piece: a new mode of synapse elimination. Neuron, 44(4), 578-580.

Kondo, T., y Raff, M.C. (2004). A role for Noggin in the development of oligodendrocyte precursor cells. Developmental Biology, 267(1), 242-251.

Kostovic, I., Lukinovic, N., Judas, M., Bognadovic, N., Mrzljak, L., Zecevic, N. et al. (1989). Structural basis of the developmental plasticity in the human cerebral cortex: the role of the transient subplate zone. Metabolic Brain Disease, 4(1), 1723.

Kostovic, I., y Rakic, P. (1990). Developmental history of the transient subplate zone in 
the visual and somatosensory cortex of the macaque monkey and human brain.

Journal of Comparative Neurology, 297(3), 1441-1470. DOI: $10.1002 /$ cne.902970309.

Kriegstein, A.R., y Noctor, S.C. (2004). Patterns of neuronal migration in the embryonic cortex. Trends in Neurosciences, 27(7), 392-399. doi:10.1016/j.tins.2004.05.001.

Kriegstein, A., y Álvarez-Buylla, A. (2009). The glial nature of embryonic and adult neural stem cells radial glial cells. Annual Review of Neuroscience, 32, 149-184. doi: 10.1146/annurev.neuro.051508.135600.

Le Douarin, N.M., y Dupin, E. (2003). Multipotentiality of the neural crest. Current Opinion in Genetics and Development, 13(5), 529-536.

Lebel, C., Walker, L., Leemans, A., y Beaulieu, P.C. (2008). Microstructural maturation of the human brain from childhood to adulthood. Neuroimage, 40(3), 1044-5. doi: 10.1016/j.neuroimage.2007.12.053.

Lenroot, R.K., y Giedd, J.N. (2006). Brain development in children and adolescence: Insights from anatomical magnetic resonance imaging. Neuroscience and Biobehavioral Review, 30, 718-729. doi:10.1016/j.neubiorev.2006.06.001.

Lewis, T.L., y Maurer, D. (2005). Multiple sensitive periods in human visual development: evidence from visually deprived children. Developmental Psychobiology, 46(3), 2977-2986.

Lim, Y., y Golden, J.A. (2007). Pattering the developing diencephalon. Brain Research Reviews, 53(1), 17-26.

Liu, J., Dietz, K., DeLoyht, J.M., Pedre, X., Kelkar, D., Kaur J., et al. (2012). Impaired adult myelination in the prefrontal cortex of socially isolated mice. Nature Neuroscience, 15, 1621-3. doi:10.1038/nn.3263. 
Long, F. (2012). Prenatal bone development. En F.H. Glorieux, J.M. Pettifor, Y H.

Jüppner (Eds.), Pediatric bone. Biology and diseases (pp. 39-54). San Diego: Academic Press.

Lossi, L., Alasia, S., Salio, Ch., y Merigui, A. (2009). Cell death and proliferation in acute slices and organotypic cultures of mammalian CNS. Progress in Neurobiology, 88(4), 221-245. doi: 10.1016/j.pneurobio.2009.01.002.

Lossi, L., Cantile, C., Tamagno, I. y Merighi A. (2005). Apoptosis in the mammalian CNS: Lessons from animal models. Veterinary Journal, 170(1), 52-66.

Lossi, L., y Merighi, A. (2003). In vivo cellular and molecular mechanisms of neuronal apoptosis in the mammalian CNS. Progress in Neurobiology, 69(5), 287-312.

Lu, L.H., Leonard, C.M., Thompson, P.M., Kan, E., Jolley, J., y Welcome, S.E., et al. (2007). Normal developmental changes in inferior frontal grey matter are associated with improvement in phonological processing: a longitudinal MRI analysis. Cerebral Cortex, 17(5), 1092-1099.

Lüer, K., y Technau, G.M. (2009). Single cell cultures of Drosophila neuroectodermal and mesectodermal central nervous system progenitors reveal different degrees of developmental autonomy. Neural Development, 4(30), 1-16. doi:10.1186/17498104-4-30.

Luskin, M.B. (1993). Restricted proliferation and migration of postnatally generated neurons derived from the forebrain subventricular zone. Neuron, 1(1), 173-189.

Makinodan, M., Rosen, K.M., Ito, S., y Corfas, G. (2012). A critical period for social experience-dependent oligodendrocyte maturation and myelination. Science, 337(6100), 1357-1360. DOI: 10.1126/science.1220845.

Mancheño Maciá, E., y Giménez Ribotta, M. (2005). ¿Es posible la reparación del cerebro? Mente y Cerebro, 15, 34-38. 
Maor-Nof, M. y Yaron, A. (2013). Neurite pruning and neuronal cell death: spatial regulation of shared destruction programs. Current Opinion in Neurobiology, 23 (6), 900-906. doi: 10.1016/j.conb.2013.06.007.

Marin-Padilla, M. (1997). Developmental neuropathology and impact of perinatal brain damage I and II. Journal of neuropathology and experimental neurology, 56(3), 219-235.

Marin, O., y Rubenstein, J.L. (2003). Cell migration in the forebrain. Annual Review of Neuroscience, 26, 441-483.

Métin, C.H., Vallee, R.B., Rakic, P., y Bhide, P.G. (2008). Modes and mishaps of neuronal migration in the mammalian brain. The Journal of Neuroscience, 28(46), 11746-11752. doi: 10.1523/JNEUROSCI.3860-08.2008.

Milet, C., y Monsoro-Burg, A.H. (2012). Neural crest induction at the neural plate border in vertebrates. Developmental Biology, 366(1), 22-33.

Moreau-Fauvarque, C., Kumanogoh, A., Camand, E., Jaillard, C., Barbin, G., Boquet, I., et al. (2003). The transmembrane Semaphorin Sema4D/CD100, an inhibitor of axonal growth, is expressed on oligodendrocytes and upregulated after CNS lesion. The Journal of neuroscience: the official journal of the Society for Neuroscience, 23(27), 9229-9239.

Mori, T., Takumi, K., Shimizu, K., Oishi, T., y Hayashi, M. (2006). Heterogeneity of the developmental patterns of neurotrophin protein levels among neocortical areas of macaque monkeys. Experimental Brain Research, 171(1), 129-138.

Ndubaku, U., y De Bellard, M.E. (2008). Glial cells: Old cells with new twists. Acta histochemica, 110(3), 182-195. Doi: 10.1016/j.acthis.2007.10.003.

Nordeen, K.W., y Nordeen, E.J. (2004). Synaptic and molecular mechanisms regulating 
plasticity during early learning. Annals of the New York Academy of Sciences, $1016,416-437$.

Parnavelas, J.G. (2000). The origin and migration of cortical neurones: new vsitas. Trends in Neurosciences, 23(3), 126-131.

Pedersen, B.K., Pedersen, M., Krabbe, K.S., Bruunsgaard, H., Matthews, V.B., y Febbraio, M.A. (2009). Role of exercise-induced brain-derived neurotrophic factor production in the regulation of energy homeostasis in mammals. Experimental Physiology, 94(12), 1153-1160. doi: 10.1113/expphysiol.2009.048561.

Pinel, J.P.J. (2007). Biopsicología. Madrid: Pearson Educación.

Rakic, S., y Zecevic, N. (2000). Programmed cell death in the developing human telencephalon. European Journal of Neuroscience, 12(8), 2721-2734.

Rao, A.A. (2013). Views and opinion on BDNF as a target for diabetic cognitive dysfunction. Bioinformation, 9(11), 551-554.

Ramón y Cajal, S. (1890). Sobre la aparición de las expansiones celulares en la médula embrionaria. Gaceta Sanitaria, 12, 413-9.

Rapoport, J.L., y Gogtay, N. (2008). Brain neuroplasticity in healthy, hyperactive and psychotic children: insights from neuroimaging. Neuropsychopharmacology, 33, 181-197. Doi:10.1038/sj.npp.1301553.

Richardson, W.D., Pringle, N., Mosley, M.J., Westermark, B., y Dubois-Dalcq, M. (1988). A role for platelet-derived growth factor in normal gliogenesis in the central nervous system. Cell, 53(2), 309-319.

Rivkin, M.J. (2000). Developmental neuroimaging of children using magnetic resonance techniques. Mental Retardation and Developmental Disabilities, 6(1), $68-80$. 
Rohlfs Domínguez, P. Factores determinantes del consumo infantil de verduras.

[Determinant factors of child vegetable consumption]. Tesis doctoral. Granada: Universidad de Granada; 2010.

Rohlfs Domínguez, P. (2011). The study of postnatal and later development of the taste and olfactory systems using the human brain mapping approach: an update. Brain Research Bulletin, 84, 118-124.

Rösner, H., Möller, W., Wassermann, T., Mihatsch, J., y Blum, M. (2007). Attenuation of actinomyosinII contractile activity in growth cones accelerates filopodiaguided and microtubule-based neurite elongation. Brain Research, 1176, 1-10.

Rossi, F., Gianola, S., y Corvetti, L. (2007). Regulation of intrinsic neuronal properties for axon growth and regeneration. Progress in Neurobiology, 81(1), 1-28.

Sadler, T.W. (2009). Embriología médica: con orientación clínica. Buenos Aires: Editorial Médica Panamericana.

Saxena, S., y Caroni, P. (2007). Mechanisms of axon degeneration: From development to disease. Progress in Neurobiology, 83(3), 174-191.

Semple, B.D., Blomgren, K., Gimlin, K., Ferriero, D.M., y Noble-Haeusslein, L.J. (2013). Brain development in rodents and humans: Identifying benchmarks of maturation and vulnerability to injury across species. Progress in Neurobiology, 106-107, 1-16. Doi: 10.1016/j.pneurobio.2013.04.001.

Snell, R.S. (2007). Neuroanatomía clínica. Buenos Aires: Editorial Médica Panamericana.

Snyder, J.S., Hong, N.S., McDonald, R.J., y Wojtowicz, J.M. (2005). A role for adult neurogenesis in spatial long-term memory. Neurosciences, 130(4), 843-52.

Snyder, J.S., Kee, N., y Wojtowicz, J.M. (2001). Effects of adult neurogenesis on 
synaptic plasticity in the rat dentate gyrus. Journal of Neurophysiology, 85(6), 2423-2431.

Sowell, E.R., Peterson, B.S., Thompson, P.M., Welcome, S.E., Henkenius, A.L., y

Toga, A.W. (2003). Mapping cortical change across the human life span. Nature Neuroscience, 6(3), 309-315.

Sowell, E.R., Thompson, P.M., Tessner, K.D., y Toga, A.W. (2001). Mapping continued brain growth and gray matter density reduction in dorsal frontal cortex: inverse relationships during postadolescent brain maturation. The Journal of neuroscience : the official journal of the Society for Neuroscience, 21(22), 88198829.

Staveley BE. Neural crest cells. In BIOL 2013. URL:

http://www.mun.ca/biology/desmid/brian/BIOL3530/DEVO_05/ch05f17.jpg [08.07.2013].

Strelchenko, N., y Verlinsky, Y. (2006). Embryonic stem cells from morula. Methods in Enzymology, 418, 93-108.

Su, Z., y He, H. (2010). Olfactory ensheathing cells: Biology in neural development and regeneration. Progress in Neurobiology, 92(4), 517-532. Doi: 10.1016/j.pneurobio.2010.08.008.

The Cochrane Collaboration (2013). Cochrane reviews. URL: http://www.cochrane.org/cochrane-reviews [26.09.2013].

Winseck, A.K., Caldero, J., Ciutat, D., Prevette, D., Scott, S.A., Wang G, et al. (2002). In vivo analysis of Schwann cell programmed cell death in the embryonic chick: regulation by axons and glial growth factor. The Journal of neuroscience : the official journal of the Society for Neuroscience, 22(11), 4509-4521.

Whitaker-Azmitia, P. M. (2010). Serotonin and Development. En R. Menzel y P.R. 
Benjamin (Eds.). Handbook of Behavioral Neuroscience (309-323). San Diego:

Academic Press.

Yang, I., Lewis, R., y Miller, R.H. (2011). Interactions between oligodendrocyte precursors control the onset of CNS myelination. Developmental, 350(1), 127138. Doi: 10.1016/j.ydbio.2010.11.028.

Yao, J.K., Windebank, A.J., Poduslo, J.F., y Yoshino, J.E. (1990). Axonal regulation of Schwann cell glycolipid biosynthesis. Neurochemical Research, 15(3), 279-282.

Yeo, W., y Gautier, J. (2004). Early neural cell death: dying to become neurons. Developmental Biology, 274(2), 233-244.

Zatorre, R.J., Fields, R.D., y Johansen-Berg, H. (2012). Plasticity in gray and white: neuroimaging changes in brain structure during learning. Nature Neuroscience, 15, 528-536. Doi:10.1038/nn.3045. 


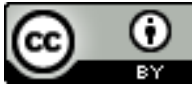

Este texto está protegido por una licencia CreativeCommons

Usted es libre para Compartir -copiar y redistribuir el material en cualquier medio o formato- y Adaptar el documen- to -remezclar, transformar y crear a partir del material- para cualquier propósito, incluso comercialmente, siempre que cumpla la condición de:

Atribución: Usted debe reconocer el crédito de una obra de manera adecuada, proporcionar un enlace a la licencia, e in- dicar si se han realizado cambios. Puede hacerlo en cualquier forma razonable, pero no de forma tal que sugiera que tie-ne el apoyo del licenciante o lo recibe por el uso que hace. 